\title{
Refugiados e nipo-descendentes: espacialidades e deslocamentos no contexto brasileiro
}

Refugees and Japanese descendants: Spatialities and displacements in the Brazilian context

\section{Igor José de Renó Machado}

Professor do departamento de Ciências Sociais, Universidade Federal de São Carlos. Diretor da EdUFSCar.

\section{Resumo}

Este artigo pretende explorar as relações entre os deslocamentos e o espaço, a partir de distintos contextos de pesquisa e reflexão. Contrastando dois conjuntos de pesquisas, pretendo produzir algumas comparações sobre a percepção do espaço entre grupos de deslocamento recente e grupos de descendentes de migrantes do começo do século XX no Brasil - respectivamente refugiados e nipo-descendentes. A comparação nos permite pensar em como determinadas espacialidades influenciam na vida desses refugiados e descendentes de imigrantes.

Palavras-chave: Nipo-descendentes, Refugiados, Espaço, Diferença.

\section{Abstract}

This article aims at exploring the relationship between displacement and space from different contexts of research and reflection. Contrasting two sets of research, I intend to produce some comparisons on the perception of space between groups of recent displacement and groups of descendants of migrants of the early twentieth century in Brazil: refugees and Japanese descendants, respectively. The comparison allows us to think about how certain spatialities influence the lives of these refugees and descendants of immigrants.

Keywords: Japanese descendants, Refugees, Space, Difference. 


\section{INTRODUÇÃO}

Este artigo pretende explorar as relações entre os deslocamentos e o espaço, a partir de distintos contextos de pesquisa e reflexão. Contrastando dois conjuntos de pesquisas desenvolvidos no Laboratório de Estudos Migratórios (LEM) da Universidade Federal de São Carlos (UFSCar), pretendo produzir algumas comparações sobre a percepção do espaço entre grupos de deslocamento recente e grupos de descendentes de migrantes do começo do século XX. Essa questão surge a partir de um desenvolvimento lento e gradual de uma abordagem alternativa sobre as migrações, que passa por uma crítica ao conceito de identidade e pela elaboração de novas perspectivas sobre a diferença, nas quais o lugar do espaço parece ter especial importância.

Em termos gerais, procuramos perceber como uma perspectiva inspirada nos trabalhos de Ingold (2007), Strathern (2014) e Wagner (2010) poderia contribuir para pensar a migração para além das dinâmicas transnacionais tão em voga desde os anos 1990 (SCHILLER; BASCH; BLANCSZANTON, 1992). O que vimos anteriormente num conjunto de trabalhos sobre Governador Valadares e região é que a própria existência da migração se deve a necessidades inscritas na ordem do parentesco. Entre outras coisas, pudemos avançar numa retomada dos conteúdos culturais e simbólicos da experiência migrante ativados pelo e no parentesco. Olhar para o parentesco como manifestação e estrutura, simultaneamente, de um modo de vida, nos deu alguns ganhos analíticos, por exemplo, entender as remessas como parte do sistema de parentesco e não como um fato econômico em si (MACHADO; STABELINI, 2011).

Outro conjunto de pesquisas sobre a experiência imigrante japonesa no Brasil ${ }^{1}$ levou-nos a perceber que o contraste entre as várias experiências se organizava em torno de diferentes parentescos nipo-descendentes, que se constituíam de formas distintas, produzindo realidades díspares, como num espectro de várias possibilidades. Se em Valadares aprendemos como

\footnotetext{
Ver Machado (2011).
} 
o parentesco é a migração, entre os descendentes de japoneses aprendemos que a migração é um conjunto variado de parentescos. São variações fractais derivadas de uma experiência migratória que já conta com mais de cem anos.

Essa percepção das diferenças levou-nos a questionar a pertinência do conceito de identidade para pensarmos a experiência imigrante (MACHADO, 2011). Percebemos que facilmente o conceito de identidade tende a constituir um grande coletivo (como a "identidade japonesa") reificado e fictício. O conjunto de "etnografias japonesas" nos mostrou que tratávamos de várias experiências que não poderiam ser reduzidas à tendência centrípeta do conceito de identidade, pois as diferenças internas a essas experiências japonesas no Brasil eram muito relevantes. Desenvolvemos o conceito de diferencialidade para lidar com essas múltiplas diferenças fractais.

Diferencialidade trata da produção de diferenças (não de identidades) e dá atenção especial à multiplicação da diferença a partir de processos que envolvem o tempo e o espaço. No caso japonês, no Brasil, tanto o tempo como o deslocamento espacial resultaram numa produção intensa de diferenças, de novas configurações em sistemas de parentesco. A ideia de que o compartilhamento dos mesmos caminhos (no tempo e espaço) produz uma vida em comum derivou das reflexões de Ingold (2007) sobre as linhas. Assim, chegamos a um ponto onde tanto o parentesco é migração como a migração produz, também, vários parentescos ${ }^{2}$.

Chegamos ao ponto atual das reflexões: uma imbricação entre parentesco e diferencialidades. Neste artigo pretendo explorar especificamente uma dimensão menos evidenciada até aqui: a importância dos diferentes tipos de deslocamento na constituição de parentescos e diferencialidades. Influenciado por Ingold (2007) e pela importância que ele dá para os caminhos, os trajetos e as linhas em termos fenomenológicos, pretendendo agora investigar como os distintos trajetos migratórios, feitos em conjunto, por grupos de pessoas, implicam em diferencialidades. Essa dimensão espacial

2 Obviamente, essa reflexão pressupõe algumas questões no que se refere a nossa definição de parentesco. Em termos gerais, pensamos numa definição bastante elástica, inspirada no trabalho de Carsten (1995). 
é especialmente evidente no caso dos refugiados que começamos a estudar: trajetórias variadas de caminhos espaciais causados por motivos alheios à vontade dos refugiados.

Analisamos dois casos de refugiadosimigrantes: os haitianos ${ }^{3} \mathrm{e}$ as mulheres refugiadas em São Paulo4 . Esses casos estão ligados a trajetórias espaciais distintas no presente, ao passo que os casos japoneses que nos interessam envolvem trajetórias espaciais e temporais diferentes. Tomamos aqui o trabalho sobre as famílias mestiças em Marília ${ }^{5}$ (mestiçagem definida sempre em termos nativos) e um trabalho sobre tatuagens "japonesas" ou de "estilo japonês" que nos remete a uma discussão sobre o corpo como espaço e fronteira ${ }^{6}$.

\section{QUESTÕES DE MÉTODO}

Antes de começar a discussão, entretanto, vale uma pequena discussão metodológica sobre a produção desses trabalhos e a comparação que pretendo realizar. São quatro pesquisas desenvolvidas no LEM, por orientandas de mestrado e doutorado, com pesquisas concluídas e em andamento. Feitas em diferentes contextos e tempos, achei oportuno reuni-las justamente pela possibilidade que apresentam de desenvolvimento do tema das espacialidades na experiência migratória. São dois grupos muito diferentes, que poderíamos separar em dois núcleos: o núcleo de deslocamentos contemporâneos, formados por haitianos e refugiadas, e o núcleo de coletividades relacionadas aos deslocamentos passados, formado por grupos diferentes de nipo-descendentes. Explico primeiramente as características de cada trabalho, para depois encaminhar a reflexão sobre a comparação que pretendo articular.

O trabalho sobre os haitianos foi produzido ao longos dos anos de $2012 \mathrm{e}$ 2013, por Rafaela Etechebere, ainda como aluna de graduação na UFSCar. Seu

\footnotetext{
3 Etecheberre (2013).

4 Almeida (2016).

5 Ver Hatugai (2017).

6 Ver Yanagiwara (2016).
} 
trabalho resultou num relatório de iniciação científica e numa monografia final de curso (ETECHEBERE, 2013), que uso como base para as citações aqui. O extenso e pervasivo trabalho de campo se iniciou em São Carlos, entre alunos haitianos na Universidade Federal de São Carlos, e se estendeu depois para redes de trabalhadores haitianos em Limeira, a partir de contatos pessoais da aluna. Essa rede de trabalhadores, principalmente homens, foi acompanhada com visitas regulares ao longo de 2013, entrevistas em profundidade e trabalho de campo intermitente (durante os meses de janeiro a março, depois durante julho de 2013).

Vale dizer aqui que estamos relacionando num polo das comparações o trabalho sobre haitianos e refugiados, dadas as semelhanças estruturais entre eles. Formalmente, os haitianos não são refugiados, e a maioria deles permanece no Brasil por meio do visto humanitário. Esse visto, como demonstram alguns autores - ver, por exemplo, Fernandes e Faria (2017) -, foi uma alternativa emergencial do Conselho Nacional de Imigração (CNIg) para regulamentar a chegada significativa de haitianos ao Brasil depois do terremoto que atingiu o Haiti em 2010. A criação do visto humanitário, direcionado especificamente aos haitianos, aconteceu em 2012, mas depois foi também estendido a sírios e venezuelanos, para os primeiros, em função da guerra na Síria, e para os segundos, por conta da grave crise no país vizinho.

Entretanto, a situação estrutural dos haitianos é muito similar à dos refugiados recém-chegados ao Brasil, fato que permite que a UNCHR, agência para refugiados da Organização das Nações Unidas (ONU), classifique a situação de haitianos no Brasil como refugee-like situation. Segundo o site da UNCHR:

This sub-category is descriptive in nature and includes groups of persons who are outside their country or territory of origin and who face protection risks similar to those of refugees, but for whom refugee status has, for practical or other reasons, not been ascertained ${ }^{7}$.

Autores como Audebert (2017), ao tratar da situação de refúgio de haitianos pelo mundo, também consideram a subcategoria "refugee-like situations",

Cf. UNHCR..., 2013. 
inserindo em sua análise o caso dos haitianos no Brasil. Também pesa nesse assemelhamento da situação de haitianos à de refugiados o fato de, antes de o visto humanitário ser criado, o pedido de refúgio no Brasil ter sido a forma de adentrarem legalmente no país enquanto esperavam a decisão do Comitê Nacional para os Refugiados (Conare). Assim, em termos gerais, é pertinente que, ao se pensar em refúgio no Brasil, pensemos também nos haitianos (e em todas as pessoas das demais nacionalidades a receber o direito de pedir visto humanitário). Nesses termos, a comparação que proponho nesse texto aproxima a situação de refugiadas africanas e de haitianos. Mas mesmo que não fosse por essa semelhança estrutural, poderíamos etnograficamente colocá-los lado a lado, dada a semelhança nas trajetórias migratórias dentro do Brasil.

Outro trabalho que sustenta as reflexões neste texto é o de Alexandra Almeida (2016), em seu doutorado ainda em andamento. O texto citado é um relatório de pesquisa em andamento sobre a situação de refugiadas em São Paulo. Aqui, a primeira diferença a ser notada é que o objeto da pesquisa não se refere a uma nacionalidade específica, mas sim a outros recortes. No caso, o recorte é de gênero (mulheres), situação legal (refugiadas ou mulheres que requereram o refúgio) e continente de origem (África). Por isso falo em "mulheres refugiadas", mas o correto seria dizer mulheres refugiadas africanas. O recorte da pesquisa se deve ao fato de que instituições brasileiras que são responsáveis por gerenciar a experiência de refúgio (instituições privadas financiadas pelo Estado) fizeram esse recorte e tenderam a juntar mulheres nessa situação em casas de abrigo temporário, por exemplo.

Acompanhando a experiência dessas mulheres, Almeida (2016) achou por bem não circunscrever o campo às nacionalidades, como é usual nas pesquisas de migração, mas sim à situação e experiência de vida no Brasil, que acabou por juntar congolesas, angolanas, senegalesas e ganesas, majoritariamente negras, em solo brasileiro, criando entre elas relações e circuitos de trocas e afetos relevantes para enfrentar a experiência de refúgio no Brasil. O campo foi realizado ao longo de oito meses, do final de 2015 até metade de 2016, depois teve continuidade em 2017, por mais nove meses. A partir de uma etnografia entre essas mulheres, Almeida estuda suas conexões, suas dificuldades no Brasil, suas estratégias 
de sobrevivência e suas narrativas sobre a vida em solo brasileiro. Em comum, essas mulheres migram sozinhas, muitas delas grávidas e apenas após um longo processo conseguem reunir a família em solo brasileiro.

Esses dois trabalhos sustentam meus argumentos na primeira parte do texto, configurando o polo relativo às migrações recentes, em situações de refúgio ou semelhantes a ela. No outro polo, o das experiências espaciais de pessoas que são marcadas pela história da migração de seus ancestrais, lidamos com nipo-descendentes em experiências distintas. Antes de especificar os dois trabalhos com os quais lido na segunda parte do texto, vale lembrar que todos os trabalhos lidam com uma característica que facilita a comparação, mesmo que em temporalidades distintas. Embora os nipo-descendentes sejam brasileiros natos, alguns já há quatro gerações, as marcas fenotípicas ainda os identificam como diferentes, seguindo a lógica do preconceito à brasileira, de Oracy Nogueira (2007). Haitianos e refugiadas africanas carregam o duplo estigma da estrangeiridade e negritude, multiplicando as dificuldades que enfrentam em solo brasileiro. Os quatro trabalhos tratam de coletivos que são identificados como diferentes a priori, mesmo que as temporalidades sejam muito distintas em relação à migração: japoneses migraram para o Brasil predominantemente na primeira metade do século XX (e lido aqui com seus descendentes), enquanto haitianos e refugiadas africanas fazem o deslocamento no momento presente.

Os dois trabalhos sobre os descendentes de japoneses lidam com situações muito diversas: um deles reflete sobre a situação de "mestiços" (em termos nativos), ou seja, aqueles que têm um dos pais não descendente. O local de pesquisa é a cidade de Marília, no interior de São Paulo, foco de migração japonesa ao longo do século XX. É em Marília, aliás, onde a clássica etnografia de Francisca Vieira foi realizada na década de 1970 (VIEIRA, 1973). No contexto da cidade marcada pela migração japonesa, Hatugai (2017) desenvolveu uma etnografia clássica, entre junho de 2016 e julho de 2017. O foco da pesquisa foi o acompanhamento cotidiano de famílias "mestiças" na cidade, produzindo diários de campo e entrevistas com os membros dessas famílias. Além disso, acompanhou também o cotidiano de algumas associações de descendentes de 
japoneses na cidade, para olhar a questão da mestiçagem por outros ângulos. O texto que tomo como base para a pesquisa é a qualificação de doutorado de Érica Hatugai (2017).

Outra pesquisa que tomo como objeto de reflexão é a desenvolvida por Paula Yanagiwara, sobre tatuadores nipo-descendentes no Brasil, com foco no estado de São Paulo, mas fazendo pesquisa também no Paraná. Aqui, o campo é menos evidente e menos clássico, pois o objeto foi composto por estúdios de tatuagem (no caso, seis estúdios) onde havia tatuadores nipo-descendentes e onde poderia haver também uma especialização em tatuagens "orientais", com influência japonesa. O campo exigiu o acompanhamento de diferentes estúdios, o foco em entrevistas e história de vida e o levantamento e análise de tatuagens realizadas. O objetivo era entender a relação desses tatuadores com uma imaginação da japonesidade traduzida num imaginário sobre as tatuagens "japonesas". O texto que tomo como base para a investigação é o relatório de pesquisa apresentado à Fundação de Amparo à Pesquisa do Estado de São Paulo (FAPESP), financiadora do projeto (YANAGIWARA, 2016) ${ }^{8}$.

Há, evidentemente, uma diferença entre os dois polos comparados de pesquisa, já que as pesquisas sobre os refugiados estão apenas no seu início, ao passo que as pesquisas sobre migração japonesa no Brasil (e de brasileiros no Japão) têm se desenvolvido ao longo dos últimos dez anos no seio do grupo de pesquisa (foram três doutorados e cinco mestrados concluídos). Isso dá aos trabalhos sobre nipo-descendentes uma base mais sólida de discussão e comparação, o que se evidencia no texto aqui apresentado. Os textos sobre o universo japonês ganham mais profundidade e mais maturidade, ao passo que os textos sobre refugiados inauguram discussões importantes, mas ainda sem a densidade analítica dos trabalhos “japoneses". É justamente dessa diferença que surgem as questões mais relevantes que continuam a impulsionar o estudo no grupo de pesquisa.

\footnotetext{
A pesquisa de Paula Yanagiwara foi realizada no contexto de um mestrado em antropologia no Programa de Pós-Graduação em Antropologia Social (PPGAS) da UFSCar, com dissertação defendida em 2018 (YANAGIWARA, 2018).
} 
A comparação entre as situações exige o conhecimento claro de que as experiências de migrantes recém-chegados e descendentes de longa data são necessariamente muito distintas, já que os aqui instalados há mais tempo têm a seu favor o domínio da língua, a cidadania brasileira, o acesso a direitos fundamentais ainda negados aos estrangeiros (como o direito de votar). As refugiadas e haitianas que compartilham conosco suas trajetórias têm, obviamente, questões mais prementes a resolver no cotidiano, como a sobrevivência, a reunião familiar, o acesso a direitos etc. Este artigo toma como ponto de partida para suas reflexões justamente essa diferença que permite pensar sobre o espaço na experiência migrante em seus limites etnográficos, poderíamos dizer. É no contraste entre essas situações muito distintas que as questões emergem e que podemos trazer novas ideias para o cenário de discussão sobre espaço e migração. Ao lidar com escalas temporais diferentes, adentramos em escalas espaciais também diferenciadas, produzindo aí um efeito explicativo interessante, objeto de reflexão na parte final deste texto9 .

\section{ESPACIALIDADES REFUGIADAS E HAITIANAS}

A questão do espaço e das espacialidades é um tema relevante para os estudos de refugiados. A pressuposição de que os refugiados são despossuídos de identidade, cultura, heranças e a ideia de que perderam algo essencial para se definirem preside muitos estudos sobre o tema. A territorialização estatal aparece como um índice de perda para os refugiados, como se o deslocamento resultasse sempre em um fato negativo. Clifford (1994) já notava essa tendência à fixidez da teoria antropológica em geral e ainda mais naquela voltada a entender justamente o movimento. Essa "sedentarização" da análise está acompanhada de um uso acrítico de conceitos de adaptação e aculturação, aos quais a antropologia já dedicou muita atenção crítica na primeira metade do século XX.

\footnotetext{
Sobre escalas em antropologia, ver Strathern (1995). Questões relativas às distintas profundidades temporais remetem à discussão sobre "espaço e profundidade" de Strathern (2002) que, embora em contexto muito distinto, podem ser pensadas na comparação aqui proposta entre distintas escalas.
} 
Um estudo efetivo do fenômeno do refúgio deveria considerar, portanto, segundo Kallius, Monterescu e Rajaram (2016), reflexões sobre as políticas de imobilidade. Os estados tentam constituir políticas de contenção da mobilidade, seja ao evitar a entrada, seja ao evitar a movimentação interna de contingentes de refugiados (o campo de refugiados seria o instrumento fundamental da política de imobilização). O desejo de estabilizar suas fronteiras e evitar os fluxos de "outros" diversos (imigrantes, refugiados) implica em constituir formas de imobilização das pessoas, com políticas muitas vezes violentas, ou mesmo "protofascistas", como afirmam os autores para o caso da Hungria e outros países europeus. Seguindo Appadurai (1988), os autores indicam como as análises sobre a imobilidade, assim como sobre a mobilidade e diversos processos de ativismo político permitem destacar as complexas imbricações entre espaço, lugar e voz política.

O estadocentrismo e sua conexão inevitável com o espaço resulta numa ideia de que os refugiados sempre estão perdendo espaço, lugar, identidade e tudo o mais. Na perspectiva de Agamben (2002) e Rancière (2004), por exemplo, o campo de refugiados pode ser visto como uma tecnologia do poder, um dispositivo de controle biopolítico (Foucault 2010), um produtor de sujeitos sem estado e, portanto, nus em sua humanidade, já que despidos da proteção do estado nação (e de seu espaço regulado). Agamben (2002) compara os campos de concentração nazistas com os atuais campos de refugiados, para afirmar que são produtores de sujeitos despidos de qualquer poder político, "nus" em sua aestaticidade ( statelessness $^{10}$ ). O campo de refugiados é um estado de exceção no qual o refugiado não é e não pode ser um cidadão. Rancière (2004) destaca a produção de sujeitos sem poder, em nome da defesa dos direitos humanitários, assim como Agier (2010) destaca como o humanitarismo tornou-se uma forma de totalitarismo contemporâneo. Nessas perspectivas, os refugiados aparecem como vítimas de um sistema que os despolitiza e oprime.

Se essas análises das relações de poder e opressão presentes na constelação institucional que regula e administra o refúgio internacionalmente são poderosas

\footnotetext{
${ }^{10}$ Sobre esse conceito, ver Goris, Harrington e Kohn (2009).
} 
e importantes, segundo Williams (2014) e Malkki (2002), elas, entretanto, acabam por reificar um refugiado despossuído de qualquer ação política e de qualquer capacidade de produzir espaço e lugar. A mesma argumentação é utilizada por Holmes e Castañeda (2016), num texto muito recente, indicando a atualidade da questão. Há algo como uma essencialização do refugiado como sujeito sem voz e sem lugar que funciona como mais uma ferramenta de exclusão. Sem desconsiderar o poder biopolítico dessas instituições, os autores pretendem tratar das subjetividades políticas refugiadas como capazes de produzir respostas e alternativas à opressão sistemática. Fassin (2007), por exemplo, analisa como refugiados estão constantemente engajados numa política da vida, tão emergente quanto a situação em que se encontram. Kallius, Monterescu e Rajaram (2016) analisam, por sua vez, um caso de ação política de refugiados sírios (em sua maioria) em trânsito pela Hungria, destacando a agência efetiva dos sujeitos.

A conexão entre a produção de nacionalismos xenófobos, racistas e excludentes e os deslocamentos (forçados ou não) é acentuada já por Hannah Arendt (2013), para quem as lógicas simbólicas de exclusão acabam por patologizar e discriminar os refugiados (como outros deslocantes). Do texto de Arendt (originalmente de 1951) até hoje, suas afirmações se provaram cada vez mais acuradas e precisas: o lugar da "crise" do refúgio na política europeia contemporânea é exemplo disso ${ }^{11}$. Butler e Spivak (2007), por sua vez, produzem uma análise sobre o refúgio que leva adiante a perspectiva de Arendt: para elas há o concurso de vários poderes em definir o refúgio como um estado anormal, produzindo por conta disso sujeitos expulsáveis, justamente por estarem fora da ordem normal das coisas e, principalmente, fora da lógica estatal internacional. Essa perspectiva nos permite entender a lógica de argumentos como os de Piscitelli (2013), ao refletir sobre como mesmo os instrumentos de proteção às pessoas que se deslocam acabam por impor a elas formas de imobilidade e contenção.

Passando aos trabalhos produzidos sobre o tema no seio do grupo de pesquisa do LEM, vemos que essas questões afetam também as experiências

\footnotetext{
${ }^{11}$ Ver Holmes e Castañeda (2016) e Valenta 2016.
} 
de refugiados no Brasil. No trabalho de Etecheberre (2013), vemos diferentes fluxos de haitianos ao Brasil: desde os que chegam como imigrantes em busca de trabalho até os estudantes beneficiados por determinados acordos entre Brasil e Haiti. Entre os dois perfis de haitianos, a autora achou identificações e diferenças, mas as similitudes indicam uma percepção espacial semelhante e marcada definitivamente pela experiência de deslocamento recente.

O grupo de trabalhadores estabelecido em Limeira foi "buscado" no Acre por um empresário local da construção civil, que concedeu emprego aos que vieram. Todos foram alojados numa mesma casa, alugada pelo empresário, já que é muito difícil alugar imóveis no Brasil sem fiadores, algo complicado de manejar entre imigrantes recém-chegados. A geografia espacial dos haitianos é constituída das experiências recentes de mobilidade: no caso dos trabalhadores de Limeira, essa espacialidade tem relação com a moradia na periferia extrema da cidade, com os circuitos de trabalho-religião-lazer e com os conflitos de trabalho latentes.

Todos esses fenômenos citados anteriormente constituem a geografia espacial desse grupo. Em primeiro lugar, temos as experiências de deslocamento recentes que marcam a perspectiva desse coletivo, que anunciam o compartilhamento das experiências, a ponderação e a comparação entre os lugares, as vidas e as possibilidades de trabalho. Alguns dos moradores são já migrantes de segunda ordem, ou seja, já eram imigrantes na República Dominicana ou no Haiti, o que configura o Brasil como uma continuidade progressiva numa trajetória de deslocamentos. Isso indica a grande transitoriedade das inserções desse grupo no tecido social brasileiro, já que se está sempre em busca da melhor opção de vida articulada pela sempre próxima chance de um novo deslocamento. Há um posicionamento político nessa perspectiva da mobilidade intensa: a recusa em aceitar condições degradantes e a impossibilidade de desenvolver uma relação mais digna com o lugar de migração leva a novas movimentações.

Isso explica a intensidade dos conflitos no mercado de trabalho, muito desfavorável aos haitianos. Vemos no caso de Limeira, a evidente exploração a partir da ideia de que os haitianos, por virem de um lugar "miserável", iriam 
se contentar com o pouco que é oferecido, com os salários muito abaixo do que recebem os brasileiros. Mas a espacialidade haitiana da transitoriedade e iminência de novos deslocamentos os coloca em uma posição crítica, de questionamento e cobrança em relação aos direitos de qualquer trabalhador no Brasil. Estão prontos a buscar um novo lugar onde não haja esse nível de exploração. Isso impõe uma geografia fugaz e transitória com os lugares de "assentamento" no Brasil.

Para lidar com essa transitoriedade e ainda construir algumas redes de sociabilidade, as estratégias parecem consolidadas: igreja e futebol são os elos que constroem com a sociedade brasileira nessa geografia cambiante. No trabalho de Etecheberre, tanto os estudantes como os trabalhadores encontram apoio e sociabilidades nas igrejas evangélicas, que os recebem e dão suporte a suas experiências de vida nos vários lugares do Brasil. Como uma espécie de "kit de sociabilidades" que podem encontrar em qualquer lugar onde estejam no Brasil. Um elemento do kit é o futebol, que tanto para estudantes como para os trabalhadores é parte fundamental da sociabilidade, por meio do qual contatos e amizades são negociadas e efetivadas, seja na periferia de Limeira, seja no ambiente universitário de São Carlos.

Futebol e igreja são campos de relações e constituem as geografias dos haitianos, sejam os estudantes ou os trabalhadores, mas há uma diferença fundamental entre os dois grupos: a hipermobilidade dos trabalhadores se contrapõe à relativa imobilidade dos estudantes. Os primeiros estão constituindo uma geografia espacial sempre próxima a um novo deslocamento. $\mathrm{O}$ grupo estudado por Etecheberre já havia se deslocado de Limeira para Santa Bárbara do Oeste enquanto a pesquisa ocorria e nos novos trabalhos a autora já mapeou novos deslocamentos para a cidade de Socorro e dessa para outros países (Chile e Estados Unidos). Vemos que esse conjunto de pessoas estabelece uma geografia móvel, intensa e sempre sujeita a novos deslocamentos. Isso tem implicações nas relações que os haitianos estabelecem entre si e entre os brasileiros. As redes formadas nesses deslocamentos acabam por gerar novas possibilidades de deslocamentos, mas, ao mesmo tempo, dificultam a produção de relações mais sistemáticas com brasileiros, por exemplo. 
Já no caso dos estudantes, a permanência maior em um lugar é fruto, obviamente, dos currículos universitários, que o exigem. Isso gera uma experiência diferente na construção de espacialidades, que no caso deles passa pelo futebol e igreja, mas que avança para uma produção de relações de amizade e parentesco (relacionalidades) com brasileiros, outros estrangeiros e ainda outros haitianos. A tendência à permanência os leva a uma inserção mais mediada por relacionamentos afetivos com brasileiros/as, como vemos nas descrições da autora, produzindo uma geografia também afetiva que, em certa medida, substitui a mobilidade extrema dos haitianos trabalhadores. É claro que esses limites são tênues e estudantes podem virar trabalhadores, caso queiram permanecer no Brasil, transitando entre diversas geografias espaciais da experiência migrante haitiana.

Quando nos voltamos para a questão dos refugiados na cidade de São Paulo, Almeida (2016) traz um relato cheio de detalhes sobre a situação específica das mulheres refugiadas, principalmente as africanas. Vemos que essa situação é muito comparável à dos haitianos, descrita por Etecheberre (2013), mas com uma distinção fundamental: a própria categoria de refúgio traz com ela toda uma burocracia e, poderíamos dizer, um ecossistema sociológico que atinge todas as dimensões da vida dessas mulheres.

A questão primeira, essencialmente espacial, após o deslocamento e a solicitação do refúgio é onde morar. Nesse sentido, o ecossistema tem seus pontos de apoio temporário, que regula a vida das mulheres por tempos que variam de seis meses a um ano e meio. Em casas de apoio, elas vivem sob a tutela do Estado, mesmo que indiretamente, já que essas casas pertencem, geralmente, a instituições religiosas que recebem recursos para atuar como apoio inicial à vida dos refugiados no Brasil.

Mas essas mulheres têm muitas dificuldades de inserção laboral, pois além de, em geral, serem mães de filhos pequenos, elas articulam outras noções de trabalho e parentesco, que desafiam a compreensão do mercado de trabalho brasileiro e suas dificuldades. Além disso, sofrem de todos os estigmas que dificultam a vida de trabalhador: são mulheres, negras, estrangeiras, sem domínio do português, moram em periferias e são mães desacompanhadas. Todos 
esses fatores diminuem a capacidade de obter empregos e, quando os obtém, aumentam a chance de serem exploradas no mercado de trabalho. Mesmo aquelas com formação superior em seus países sofrem grandes dificuldades para obter qualquer emprego.

Isso as limita a uma geografia da assistência, articulada por ONGs com financiamento do governo, que inaugura um jogo complexo de mercantilização da cultura dos refugiados que, tornada em mercadoria, sustenta a própria existência dessas ONG. Em troca, o assistencialismo, os empregos informais e a chance de ganhar algum dinheiro esporadicamente. Mas o ecossistema que envolve a burocracia do refúgio deu ensejo a uma "ecologia assistencialista" das ONG, financiando mais os agentes e burocratas do sistema e menos os refugiados em si. A espacialidade resultante dessa situação é uma apropriação limitada das possibilidades da vida em São Paulo, restrita às periferias, com poucas chances de uma vida econômica justa.

A situação precária de grande dificuldade de inserção laboral, seja pela dificuldade intrínseca do mercado, seja pelas diferenças culturais que tornam os regimes de trabalho brasileiro em algo sem sentido prático às refugiadas, leva a uma espacialidade dependente desse ecossistema institucional, que resulta numa espécie de perpetuação dessa situação de vulnerabilidade. Uma espacialidade fraturada entre péssimas condições de moradia, dificuldade para conseguir creches para os filhos, impossibilidades de deslocamento urbano pela falta de dinheiro. Esse laço de dependência só se quebra com a assistência familiar, quando algum parente chega e ajuda a enfrentar a situação ou quando, finalmente, essas mulheres deslocam-se novamente para outros países, assim como os haitianos. Aqui, novamente, a ação política das mulheres está na produção de novos deslocamentos, uma forma de recusa das condições que são impostas pelo ecossistema do refúgio no Brasil.

Assim, a situação imediata impede uma apropriação da cidade e seus espaços, indica um confinamento espacial, circunscrito à extrema periferia e às instituições do ecossistema do refúgio. Uma opção de fuga dessa espacialidade limitada e dependente é quando algumas igrejas (em geral evangélicas) atuam para produzir novas socialidades e outras possibilidades de assistencialismo, 
às vezes produzindo opções de trabalho dentro de uma comunidade de fé. Vemos que a espacialidade dependente precisa ser rompida para uma experiência menos amarga no Brasil, mas muitas vezes esse rompimento significa uma busca por outro deslocamento na procura por novas espacialidades.

\section{ESPACIALIDADES JAPONESAS}

O caso da experiência de descendentes japoneses no Brasil é muito distinto. Temos aqui gerações de descendentes que são cidadãos brasileiros, com direitos completos e sem restrições legais. A questão do espaço nesse coletivo enorme e muito diferenciado internamente segue outras linhas que as sucessivas movimentações de refugiados e haitianos. Aqui, exploraremos uma dimensão inesperada e relevante da espacialidade nipo-descendente: a questão de como o corpo assume o lugar de fronteira e limite nas diferentes experiências de vida desses descendentes.

Hatugai (2017) nos apresenta uma etnografia sobre as famílias "mestiças" em Marília. Como um termo nativo, "mestiço" indica, nesse contexto, aqueles que são filhos de brasileiros não descendentes com descendentes de japoneses. O termo, nos contextos de pesquisa, não abarca o sentido tradicional brasileiro para "mestiçagem", pois Hatugai explica que o nipo-mestiço (usarei esse termo para facilitar a escrita) vive entre duas classificações antagônicas, uma por parte da comunidade nipo-descendente e outra por parte dos não descendentes. Os primeiros tendem a avaliar os mestiços como uma diferença a mais, nem japoneses, nem meio japoneses, mas "algo japoneses", num caminho de perda de algo que seria característico da "raça" (também esse um termo nativo). Já os segundos os tomam apenas como japoneses, a depender de como o fenótipo se apresenta: caso sejam identificáveis os traços japoneses, japoneses serão.

Uma classificação fenotípica predomina de um lado, mas também opera do lado dos próprios descendentes "puros". Opera, no sentido de constituir uma ideia de estética favorecida dos mestiços, pois alguns traços ocidentais de beleza são valorizados (como os olhos arredondados). Mas, se a beleza atribuída é 
uma questão importante, ao mesmo tempo ela isola o mestiço do grupo "puro", pois indica uma diferença que reflete na pessoalidade do mestiço, que não teve condições de ter uma educação completamente influenciada pela japonesidade dos pais. Um pai ou uma mãe não descendente limita, portanto, a possibilidade dos mestiços serem também "japoneses".

Hatugai (2017) nos mostra, entretanto, que o cálculo da mestiçagem é algo muito complexo, operando em vários níveis com critérios diferentes. Nem todo mestiço é igual, como bem pode um descendente "puro" ser "falso". Há outros índices de aproximação ao polo de japonesidade "pura" ou à brasilidade distante. Esses índices passam pela alimentação, tema central em qualquer associação japonesa no Brasil. Comer ou ter crescido comendo a apropriada comida japonesa pode melhorar a condição do mestiço, no sentido de aproximá-lo do polo "puro", mas apenas na medida em que exponha publicamente a prática, a participação nas festas com alimentação japonesas, etc. Isso implica em pensar num corpo modelado para um sentido específico de japonesidade, que pode até passar por cima, em certa medida, da mestiçagem. Por isso a importância das avós na alimentação é tão fundamental para a avaliação de mestiçagem dos nipo-descendentes em Marília: se a avó (descendente) está presente e cozinha a comida correta para os netos, menos "não japoneses" eles são.

O cálculo leva em consideração tanto o fenótipo quanto a história familiar de proximidade ou não com coisas japonesas. A participação ativa nas associações pode fortalecer a percepção de que um mestiço é mais puro que outro mestiço sem o histórico familiar de participação. Mas uma noção de "sangue" muito forte também é notada, como se aquilo que define um descendente autêntico estivesse contido no sangue, o que faria dos não mestiços mais autênticos que os demais. Isso instaura contas de porcentagens de sangue (inteiros, meios, quarteirões) que são também índices de estrangeiridade: quanto menos sangue, menos puro e mais distante de algo visto como autêntico. Mas essa conta é ponderada pelos itens que vimos anteriormente, a comida e a experiência de vida e não é, de toda forma, a mesma em todos os lugares.

Hatugai (2017) mostra que há diferenças nas formas como grupos ligados às associações ou a uma igreja evangélica "japonesa” constituem suas noções 
do que é ser japonês: na igreja, o uso do butsudan (relicário domiciliar para culto aos ancestrais) não é um índice de japonesidade, pois são todos "cristãos" e não mais acreditam nesses costumes. Mas, seja na igreja ou na associação, há uma tentativa dos vários descendentes de produzir casais que gerem mais "pureza”, em certo sentido. Há uma opção privilegiada de produzir casamentos entre descendentes e reverter processos de miscigenação, por exemplo.

O que todo esse cenário de complexidade nos diz sobre o espaço ou as noções de espacialidade? Aqui, tudo caminha para o corpo, para o corpo como fronteira, como bem define Hatugai (2017). No contexto de Marília, o corpo é uma geografia de definição de pertenças ou exclusões, indicando como as políticas de diferença se apropriam de formas muito inesperadas das percepções de espaço. Aquilo que separa ou une, aquilo que define grupos de similaridade ou diferença, é justamente o corpo, a produção do corpo. Desse modo, o mestiço aparece como fronteira liminar entre descendentes e não descendentes, sem ser exatamente o meio termo entre eles: é exterior aos descendentes e também exterior aos não descendentes.

O corpo mestiço inaugura uma geografia de exterioridades, de não pertencimento, de travessias para se chegar a um polo ou outro. É preciso, por assim dizer, atravessar exterioridades para atingir o pertencimento: no sentido de uma vida exemplar de japonesidade ou no fato fortuito de parecer menos ou mais japonês aos olhos dos não descendentes. Essa é uma construção de noções simbólicas de espaço (e tempo), pois implicam numa imaginação geográfica das diferenças expostas nos corpos, no sangue e no fenótipo. O espaço dos semelhantes passa a ser um corpo compartilhado, uma similitude presumida e absolutamente fluída e relativa. Mas o corpo como fronteira é uma construção alternativa de noções espaciais para guiar os movimentos desses sujeitos pela vida: seja na busca de purificação (como buscam os que querem rejaponesizar a própria prole), seja na busca de um afastamento e "abrasileiramento". O interessante é notar que o espaço simbólico aqui é tangencial à geografia "real" e efetiva da vida cotidiana, mas é responsável por delimitar mundos separados e distintos, por onde circulam as pessoas e por onde devem ou deveriam circular. O corpo é um espaço complexo na Marília dos descendentes, mestiços ou não. 
O trabalho de Yanagiwara (2016), por sua vez, apresenta a centralidade da questão do corpo numa geografia das japonesidades. Ao colocar sua própria experiência como descendente em ressonância com algumas bibliografias antropológicas e com uma perspectiva da autoantropologia, nos traz elementos para pensar a espacialidade do corpo em outros contextos. Temos o corpo como espécie de última geografia espacial da diferença nipo-descendente, como limiar que define os limites da diferença em muitos contextos ou, como a chama Yanagiwara, "a caixa".

A caixa é uma metáfora para a solidificação de estereótipos e determinadas representações hegemônicas sobre os japoneses produzidas na sociedade brasileira, por um lado, e também um conjunto de sentimentos, conhecimentos e experiências supostamente compartilhados pelos nipo-descendentes e que atuam como pressuposições e não ditos nas relações entre nipo-descendentes. Dessa maneira, a autora desenvolve uma nova dimensão de reflexão sobre a diversidade nipo-descendente (ou sobre as japonesidades): ao lado dos pressupostos da equação, que na prática opera como elemento de obscurecimento das relações, já que esses pressupostos não são, de forma alguma, realmente compartilhados por todos. São como autoestereótipos atribuídos por nipo-descendentes a si mesmos, mas sempre a partir das próprias experiências singulares, ainda que em diálogo com certas representações hegemônicas dos japoneses no Brasil.

Na sua primeira iteração ${ }^{12}$, essa perspectiva elucida como uma entrevista com o tatuador nipo-descendente resulta numa inviabilidade de comunicação, dada a profusão de pressupostos que não eram efetivamente compartilhados, impossibilitando o mero desenvolvimento de uma conversa. Na segunda iteração, o foco se dá justamente na pressuposição da homogeneidade japonesa no Brasil e em certas implicações para a análise social dessa questão, destacando novamente a diversidade e singularidade das experiências nipo-descendentes no Brasil. A reflexão nessa iteração leva à questão do fenótipo como uma chave de ativação da homogeneidade e dos impactos que isso opera na vida cotidiana

\footnotetext{
${ }^{12} \mathrm{O}$ texto de Yanagiwara é composto por três iterações.
} 
dos nipo-descendentes. Novamente, vemos o corpo agir como espacialidade da diferença, como nova fronteira, agora entre supostos japoneses e não japoneses, assim como no exemplo de Hatugai (2017).

A terceira e final iteração, por sua vez, nos leva a outro mundo de conexões e relações entre nipo-descendentes e conta a história do corpo como ativador de japonesidades nas relações intradescendentes, ao buscar uma reflexão sobre dádiva e dívida entre nipo-descendentes, explorando uma sequência de situações que poderíamos pensar serem "dramas sociais". O que as micro histórias nos dizem é que há também cálculos de espacialidade sendo conduzidos entre os descendentes que agem na facilitação de determinadas relações, atreladas, segundo Yanagiwara, a características de formação de parentesco nipo-descendente. O corpo como um espaço de ativação de circuitos de reciprocidade nos indica como determinadas espacialidades ultrapassam a mera geografia e consolidam relações de "vizinhança" a partir da fenotipia, que traz com ela algumas considerações de possibilidades de relação entre nipo-descendentes, ainda que eles não se conheçam. O corpo estabelece, por assim dizer, um campo comum de possibilidades, no qual podemos pensar numa geografia do encontro nesse mar de singularidades que são as japonesidades no Brasil.

Essa "geografia do encontro", esse "campo comum", ou um certo platô de possibilidades nos permite esticar a noção de espaço para a constituição e percepção das corporalidades, para uma concepção geográfica do corpo como potencial agenciador de espaços de relação em comum. Ao mesmo tempo, essa mesma geografia corporal resulta também numa fronteira às vezes intransponível, entre nipo-descendentes e não descendentes. Pode ser vista, inclusive, como cárcere simbólico, aqui um corpo-símbolo de diferença e separação, fato que atormenta a experiência de muitos e alimenta o que Paula Yanagiwara (2016) chama do "desejo de indistinção", que secreta muitas das subjetividades nipo-descendentes. Mas essa indistinção é também em si um fato complexo, pois é cheia de ambiguidades: indistinção nem sempre possível, às vezes desejável, frequentemente estabelece de antemão a forma como relações se estabelecerão. Corpo como espaço geográfico de relações, assim como no caso de Hatugai (2017), em que o corpo opera como fronteira entre mestiços e não mestiços. 


\section{CONSIDERAÇÕES FINAIS}

A história da antropologia é uma história sobre a questão do espaço e tempo, de como essas categorias são atravessadas pela vida social, desde os trabalhos de Durkheim sobre o totemismo, passando pela etnografia de EvansPritchard sobre os Nuer, até as etnografias contemporâneas sobre aeroportos (Augê), espaços urbanos (Magnani), entre muitas outras variáveis. O livro Os nuer, por exemplo, exibia como o tempo relativo à vida social era refletido nas organizações e percepções espaciais. Ou seja, temos uma conexão tempo/espaço em termos sociais. Gupta e Ferguson (1992) desconectaram espaço e lugar, falando de uma geografia estatal da concepção necessária de espaço, que não pode ser vista como "natural" ou "necessária" (e o caso dos refugiados sempre deixou isso bem claro). A teoria transnacional demonstra, por sua vez, como fluxos distintos constituem a experiência de migrantes (SCHILLER; ÇAĞLAR, 2010) e espacialidades duplas incidem na vida desses sujeitos em movimento.

Considerando essas perspectivas sobre o lugar do espaço/lugar na produção da vida cotidiana das pessoas em suas experiências individuais e coletivas, chegamos a determinadas reflexões, tendo como pano de fundo as diversas etnografias produzidas que discutimos ao longo do texto. De uma percepção na qual o espaço é acessório compulsório à construção das identidades, culturas e diferencialidades, passamos a uma compreensão que o espaço só existe em si ou ganha alguma significância efetiva a partir das experiências dos sujeitos. O espaço é, portanto, contingente às trajetórias de vida, surgindo como um efeito prático da vida das pessoas, ganhando sentido como maneiras de sustentar formas de experiência individual e coletiva. No caso de gente em movimento, por diversas razões, a questão espacial ganha novas dimensões, pois indica a potencialidade de conexões serem montadas gradualmente com novas realidades.

No caso de grupos que se deslocam, seja por quais razões, o espaço é também contingente ao próprio deslocamento, sendo produzido em relação às trajetórias variáveis dos grupos, às linhas que desenham ao longo de suas histórias de vida. Isso quer dizer que o espaço assume diferentes formas nas 
experiências de deslocamento, diferentes significados, todos relacionados ao sentido que os sujeitos produzem de suas movimentações. Isso explica, em grande medida, a variação extrema exposta pelos exemplos que configuram este artigo: desde as trajetórias amedrontadas de refugiados em deslocamento constante, até o conforto espacial definido de uma trajetória de deslocamentos que se deu no passado e gerou uma geografia que se espacializa em corpos mestiços. Essa produção de diferenças é a dimensão fundamental da diferencialidade como conceito. Os exemplos trabalhados aqui evidenciam como o espaço é uma função da produção das diferenças, um precipitador de diferencialidades. ${ }^{13}$

Entre esses dois grupos temos extremos de configurações de uma percepção do espaço relacionada aos deslocamentos. Os exemplos aqui trazidos nos ajudam a pensar essa intensa variação das espacialidades migrantes, sempre conectadas integralmente às suas próprias experiências de vida. Apresentamos quatro extremos de espacialidades migrantes, mas os dois grupos gerais expõem diferenças que precisamos considerar: o caso dos refugiados versus o caso dos descendentes de japoneses no Brasil evidencia questões importantes e, ao menos, um insight sobre a relação entre espaço e migração.

As espacialidades refugiadas são evidentemente mais urgentes, intensas e sempre prestes a iniciar outro deslocamento. A questão da espacialidade ainda não tem a profundidade que vemos entre os nipo-descendentes e podemos seguramente inferir que isso se deve ao pouco tempo de chegada no Brasil, sem o tempo de desenvolver o aprofundamento em direção ao corpo e ao simbólico que vimos entre os nipo-descendentes. A dificuldade de inserção e a vida complexa e dependente do ecossistema do refúgio no Brasil é o sintoma mais evidente dessa urgência, dessa impossibilidade de construir espacialidades que se interconectem com as cidades, com o país,

\footnotetext{
${ }^{13}$ A antropologia brasileira também produz interessantes reflexões sobre noções como "espacialidade", principalmente em contextos urbanos. Ver Frugoli Júnior(2005) e Magnani (2005), entre outros. A noção adotada aqui de espacialidade pressupõe sempre um processo de apropriação do espaço pelos sujeitos, processo que é constitutivo de suas diferenças. Obviamente, em determinados contextos, como os que enfrentam os refugiados, essa dimensão de sua vida é dificultada socialmente e a apropriação do espaço é muito limitada.
} 
dessa restrição à esfera delimitada do ecossistema do refúgio. Fugir dessa limitação para constituir espacialidades mais livres é uma grande dificuldade, às vezes, apenas resolvida com novas movimentações e o início de novos processos de relação em novos espaços. Vemos que as recentes movimentações forçadas impelem, no Brasil, a insegurança na experiência cotidiana, a incerteza sobre a capacidade de inserção no mercado de trabalho e a extrema dependência do ecossistema do refúgio. Isso os leva a espacialidades urgentes, limites, quase sempre empurrando a novas movimentações, como vimos entre haitianos e africanas.

Já as espacialidades japonesas (simplificando o termo) no Brasil estão profundamente enraizadas na experiência social cotidiana, apresentando suas especificidades apenas quando caminham para o corpo ou para o simbólico. Nesse caso, o espaço da diferença é articulado ao redor da experiência do corpo, por exemplo. O corpo aparece aí como fronteira espacial num conjunto de pessoas que compartilha espacialidades com outros brasileiros, mas que despertam para suas especificidades na fronteira espacial que envolve seus corpos e suas apreensões por outros descendentes e por não descendentes.

Pode-se dizer que o efeito do tempo na produção do espaço, considerando que a migração japonesa é antiga e o deslocamento de refugiados extremamente recente, é uma inserção nas espacialidades nacionais e a constituição lenta de novas espacialidades em torno da experiência de diferença, atrelada aqui aos corpos e ao simbólico. Temos espacialidades não espaciais, poderíamos dizer, na medida em que são espacialidades fronteiriças aos corpos e ao simbólico. As espacialidades refugiadas, prementes, urgentes, recentes, são processos em plena construção no seio de um ecossistema que dificulta qualquer estabilidade e que gera continuamente uma dependência instável, constituindo uma geografia que os refugiados sentem como limitadora. As espacialidades, ali, aparecem como limites, como obstáculos a uma vida que se acomode de alguma forma à sociedade brasileira. Essa espacialidade limite gera novos deslocamentos ou a premência constante de sua possibilidade.

Vemos que o tempo gera, portanto, uma dinamização na produção das diferenças e espacialidades, ao contrastarmos os dois grupos de trabalhos. 
A instabilidade espacial é o cotidiano dos refugiados e seus deslocamentos forçados, instabilidade que parece ser cuidadosamente mantida pelo ecossistema do refúgio no Brasil, quase como estratégia de não integração efetiva à sociedade brasileira. Capturados pelo ecossistema, os refugiados estão sempre prestes a escapar com novos movimentos e novas tentativas de produzir espacialidades mais confortáveis e menos instáveis.

\section{REFERÊNCIAS}

1. AGAMBEN, Giorgio. Homo sacer: o poder soberano e a vida nua. Belo Horizonte: Editora UFMG, 2002.

2. AGIER, Michel. Humanity as an identity and its political effects: a note on camps and humanitarian government. Humanity, Philadelphia, v. 1, n. 1, p. 29-46, 2010.

3. ALMEIDA, Alexandra C. G. Reflexões sobre a questão do refúgio na cidade de São Paulo: o caso das mulheres africanas. São Carlos: Universidade Federal de São Carlos, 2016. Relatório de pesquisa.

4. APPADURAI, Arjun. Introduction: place and voice in anthropological theory. Cultural Anthropology, Hoboken, v. 3, n. 1, p. 16-20,1988.

5. ARENDT, Hannah. Origens do totalitarismo. São Paulo: Editora Companhia das Letras, 2013.

6. AUDEBERT, Cedric. The recent geodynamics of Haitian migration in the Americas: refugees or economic migrants? Revista Brasileira de Estudos de População, São Paulo, v. 34, n. 1, p. 55-71, 2017.

7. BUTLER, Judith; SPIVAK, Gayatri. Who sings the Nation-state? Language, Politics, Belonging. Oxford: Seagull Books, 2007.

8. CARSTEN, Janet. The substance of kinship and the heat of the hearth: feeding, personhood and relatedness among Malays in Pulau Langkawi. American Ethnologist, Hoboken, v, 22, n. 2, p. 223-241, 1995.

9. CLIFFORD, James. Diasporas. Cultural Anthropology, Hoboken, v. 9, n. 3, p. 302-338, 1994.

10. ETECHEBERRE, Rafaela. Haitianos: refugiados ou imigrantes? Uma antropologia sobre a perspectiva legal do refúgio no Brasil. São Carlos: Universidade Federal de São Carlos, 2013. Relatório de pesquisa. 
11. FASSIN, Didier. Humanitarianism as a politics of life. Public Culture, Durham, v. 19, n. 3, p. 499-520, 2007.

12. FERNANDES, Duval; FARIA, Andressa Virgínia de. O visto humanitário como resposta ao pedido de refúgio dos haitianos. Revista Brasileira de Estudos de População, São Paulo, v. 34, n. 1, p. 145-161, 2017.

13. FOUCAULT, Michel. Do governo dos vivos: curso no Collège de France, 19791980 (excertos). Tradução de Nildo Avelino. São Paulo: Centro de Cultura Social, 2010.

14. FRUGOLI JÚNIOR., Heitor. O urbano em questão na antropologia: interfaces com a sociologia. Revista de Antropologia, São Paulo, v. 48, n. 1, p. 133-165, 2005.

15. GORIS, Indira; HARRINGTON, Julia; KOHN, Sebastian. Statelessness: what it is and why it matters. Forced Migration Review, Oxford, n. 32, p 4-7, 2009.

16. GUPTA, Akhil; FERGUSON, James. Beyond "culture": space, identity, and politics os difference. Cultural Anthopology, Hoboken, vol. 7, n. 1, p. 6-23, 1992.

17. GUPTA, Akhil. The song of the nonaligned world: transnational identities and the reinscription of space in late capitalism. Cultural Anthopology, Hoboken, vol. 7, n. 1, p. 63-79, 1992.

18. GUPTA, Akhil; FERGUSON, James. Anthropological locations: boundaries and grounds of a field science. Berkeley: University of California Press. 1997.

19. HATUGAI, Érica Rosa. Um corpo como fronteira: parentesco e identificação entre descendentes nipônicos “mestiços”. São Carlos: Universidade Federal de São Carlos, 2017. Qualificação de doutorado.

20. HOLMES, Seth M.; CASTAÑEDA, Heide. Representing the "European refugee crisis" in Germany and beyond: deservingness and difference, life and death. American Ethnologist, Hoboken, v. 43, n. 1, p 1-13, 2016.

21. INGOLD, Tim. Lines: a brief history. London: Routledge, 2007.

22. KALliUS, Annastina; MONTERESCU, Daniel; RAJARAM, Prem Kumar. Immobilizing mobility: border ethnography, illiberal democracy, and the politics of the "refugee crisis" in Hungary. American Ethnologist, Hoboken, v. 43, n. 1, 2016.

23. MACHADO, Igor J. R.; STABELINI, Fábio. Remessas como relações: reflexões não-economicistas sobre a circulação de remessas entre famílias transnacionais. In: FLOREZ, Fernando C.; MALAMUD, Andrés. Migrações, coesão social e governação: perspectivas Euro-Latino-Americanas. Lisboa: Imprensa de Ciências Sociais, 2011. p. 92-111.

24. MACHADO, Igor J. R. (org.). Japonesidades multiplicadas: novos estudos sobre a presença japonesa no Brasil. São Carlos: EdUFSCar, 2011. v. 1. 
25. MAGNANI, José G. C. Os circuitos dos jovens urbanos. Tempo Social, São Paulo, v. 17, n. 2, p. 173-205, 2005.

26. MALKKI, Liisa H. National Geographic: the rooting of peoples and the territorialization of national identity among scholars and refugies. Cultural Anthopology, Hoboken, v. 7, n. 1, 1992.

27. MALKKI Liisa $\mathrm{H}$. News from nowhere: mass displacement and globalized "problems of organization". Ethnography, Thousand Oaks, v. 3, n. 3,p. 351-360, 2002.

28. NOGUEIRA, Oracy. Preconceito racial de marca e preconceito racial de origem: sugestão de um quadro de referência para a interpretação do material sobre relações raciais no Brasil. Tempo Social, São Paulo, v. 19, n. 1, p. 287-308, 2007.

29. PISCITELLI, Adriana. Brasileiras nos mercados transnacionais do sexo. Rio de Janeiro: Editora Uerj, 2013. (Coleção Sexualidade, Gênero e Sociedade).

30. RANCIÈRE, Jacques. Who is the subject of the rights of man? The South Atlantic Quarterly, Durham, v. 103, n. 2-3, p. 297-310, 2004.

31. SCHILLER, Nina Glick; BASCH, Linda; BLANC-SZANTON, Cristina. Transnationalism: A new analytic framework for understanding migration. Annals of New York Academy of Sciences, New York, v. 645, n. 1, p. 1-24, 1992.

32. SCHILLER, Nina Glick; ÇAĞLAR, Ayşe. Locating migration: Rescaling cities and migrants. Ithaca: Cornell University Press, 2010.

33. SCHILLER, Nina Glick; FAIST, Thomas (eds.). Migration, development, and transnationalization: a critical stance. New York: Berghahn Books, 2010.

34. STRATHERN, Marilyn. Shifting contexts: transformations in anthropological knowledge. London: Routledge, 1995.

35. STRATHERN, Marilyn. On space and depth. In: LAW, John; MOL, AnneMarie. (eds.). Complexities: social studies of knowledge practices. Durham: Duke University Press, 2002. p. 88-115.

36. STRATHERN, Marilyn. O efeito etnográfico e outros ensaios. São Paulo: Cosac Naify, 2014.

37. UNHCR. Statistical Online Population Database: sources, methods and data considerations. The UN Refugee Agency, Genebra, 1 jan. 2013. Disponível em: https://goo.gl/KnCwEh. Acesso em: 23 maio 2018.

38. VALENTA, Marko. Welcome, but please don't stay: refugee crisis' implications in the South-East European countries. In: ISA FORUM OF SOCIOLOGY, 3., 2016, Vienna. Annals [...]. Madrid: International Sociological Association, 2016. 
39. VIEIRA, Francisa I. S. O japonês na frente de expansão paulista: o processo de absorção do japonês em Marília. São Paulo: Pioneira, 1973.

40. WAGNER, Roy. A invenção da cultura. São Paulo: Cosac Naify, 2010.

41. WILLIAMS, Christian. Refugees and social theory: from the politics of "bare life" to refugees as political subjects. Acta Academica, Bloemfontein, v. 46, n. 4, p. 117-31. 2014.

42. YANAGIWARA, Paula. S. Três iterações sobre a tatuagem japonesa no Brasil. São Carlos: Universidade Federal de São Carlos, 2016. Relatório de pesquisa.

43. YANAGIWARA, Paula S. Os processos de construção de diferenças entre tatuadores nipo-descendentes no Brasil. Dissertação (Mestrado em Antropologia Social). Universidade Federal de São Carlos, São Carlos, 2018. 